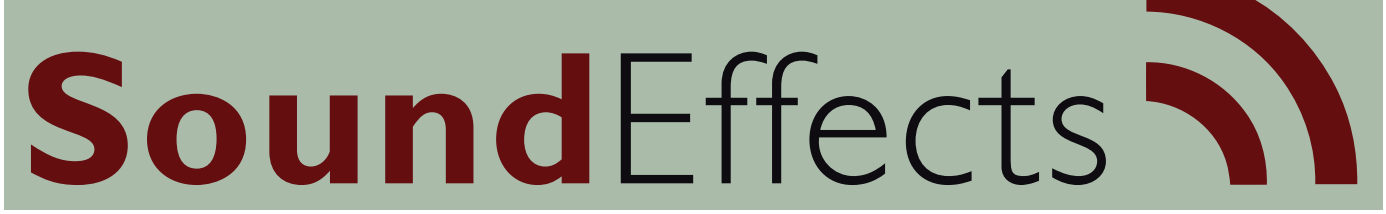

An Interdisciplinary Journal of Sound and Sound Experience

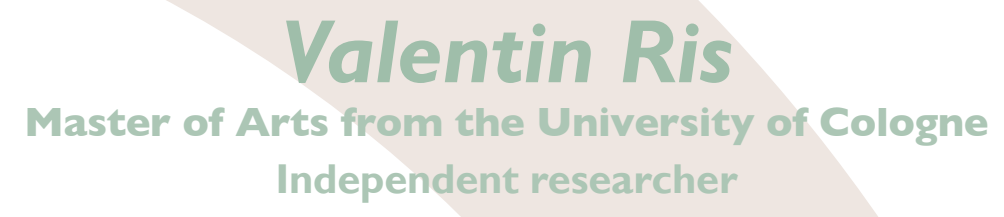

\title{
The Environmentalization of space and listening
}

An archaeology of noise-cancelling headphones and Spotify's concentration playlists 


\begin{abstract}
This paper aims to analyze the relationship between listening techniques and technologies and forms of subjectivation in our current auditory culture compared to mid-20th century practices. Applying a media archaeological approach in order to unearth underlying histories of knowledge of the discussed technologies and practices offers a way of understanding how subjectivations and the constitution of environments in the context of large power regimes are intertwined. Against the theoretical backdrop of Gilles Deleuze's text on "societies of control" and Erich Hörl's notion of "Environmentalization", the paper outlines conceptualizations of environments in different forms of sonic control that are inherent in practices and technologies of noise-cancelling headphones and specific Spotify playlists. The listening spaces that emerge in the analyzed practices/technologies reveal continuities as well as discontinuities when compared to their historical predecessors. Both the current phenomena are characterized by a process of advancing cybernetization and thus the formation of controllable environments. The depicted transformation corresponds to Deleuze's observation of a new paradigm of power which he characterized as a shift from "molding" to "modulation", i.e. a shift from a form-imposing to a self-regulating mode of power. Spotify's concentration playlists and noisecancelling headphones both operate based on the principle of modulation and represent modes of environmental technologies. In the consideration of the subject-environment relationship on the other hand, current forms of subjectivation become apparent in cybernetic visions of control and environmental power. It is thus shown that listening spaces offer an approach to analyzing power and subjectivation.
\end{abstract}

\title{
Introduction
}

In the beginning of the COVID-19 pandemic in 2020, many employees who were lucky enough not to lose their jobs started working from home. At the same time, Spotify (2020) recorded a strong increase in user activity in the period from April 17 to May 17, 2020. Playlists with themes relative to "work-from-home" recorded an enormous growth of $1,400 \%$ compared to the beginning of March, at a time when, in most Western countries, no action had yet been taken to prevent the spread of the coronavirus (Spotify, 2020). It must be assumed that there is a correlation between adapting to the new situation of working remotely and the increase in listeners of certain playlists. In this context, listening to music follows instrumental goals and, presumably, work-from-home playlists are used for self-motivation and mood control by means of "uplifting" music or to focus on work by blocking out disruptive sonic events of the environment.

Music consumption for instrumental or self-optimizing purposes has been widely discussed as a common contemporary listening practice in the music-soci- 
ological literature. For instance, Tia DeNora (2000) coined the term "Technology of the Self" based on ethnographic interviews and emphasized how music is used to regulate, affect or form identity. In a similar perspective, Michael Bull $(2000 ; 2007)$ stressed in his ethnographically influenced studies how the use of personal stereos and iPods enables individuals to create a personalized and atomistic listening space. In the public and in daily life, music and portable listening devices help people to manage their time and way through public space.

In current debates on the consequences of the digitalization of music-music streaming, sound files, playlists, platform capitalism etc.-similar arguments are reiterated and turned into a more critical perspective. Combined with common observations of a "surveillance capitalism" (Zuboff, 2019), these approaches are mainly concerned with aspects of a new normative and hyper-individualized way of listening (Eriksson \& Johansson, 2017; Drott, 2018) through (algorithmically) curated playlists (Prey, 2018) or focus on mood regulation (Anderson, 2015). Consequentially, key concepts deal with analyzing inherent forms of algorithmic control and surveillance or unveil subjectivations, especially neoliberal ideologies, described as "disciplinary power" or "Technology of the Self" (Eriksson et al., 2019; Haberer, 2020). In short, familiar patterns of description from cultural studies, which are focused on subjectivation and self-optimization, are transferred to the new topic of the digital distribution of music and other listening technologies such as noise-cancelling headphones (Hagood, 2019).

In the following, I would like to set a different focus in the examination of Spotify's "concentration playlists" and noise-cancelling headphones. By applying a media archaeological approach, I unearth underlying histories of knowledge of the discussed technologies and aesthetic practices. At the same time, this approach primarily aims at revealing historically specific space and thus environment configurations which in turn imply corresponding forms of subjectivation.

The first section discusses the two main categories for the subsequent arguments regarding space and environment. It then offers a short interpretation of Gilles Deleuze's essay "Postscript on the Society of Control" (1992) which proposes a new paradigm of power in relation to the notion of "Environmentalization" (Hörl 2018), describing a more general transformation of power, subjectivity, knowledge and capital. The second section deals with the historical evolution and the associated imaginations of Active Noise Control (ANC) and offers a more detailed look at a current Sony advertising campaign and the subject-environment relation it represents. The third section traces the spatial and environmental logics of Spotify's concentration playlists back through their historical predecessor Muzak to the concept of perception within experimental psychology in the late 19th century. Finally, I summarize the various alterations from the perspective of a "general ecology". 
Thus, a process of ongoing "Environmentalization" becomes apparent on the level of technologies as well as on the level of listening techniques. ${ }^{1}$

\section{Space, control and Environmentalization}

In humanities, the so-called "spatial turn" put space center stage. Subsequently, a very diverse range of theories on space formed. What these theories have in common is that space is no longer understood as an "absolute", but as a relational category. Accordingly, for human geographer Nigel Thrift (2009), the different writings on space share a similar ambition:

[T]hey abandon the idea of any pre-existing space in which things are embedded [...] for an idea of space as undergoing continual construction through the agency of things encountering each other in more or less organized circulations. This is a relational view of space in which, rather than space being viewed as a container within which the world proceeds, space is seen as a co-product of those proceedings (p. 86).

Drawing on such conceptualizations of space as a socio-technological configuration, Georgina Born (2013) suggests a relational understanding of sound/music and space in order to reveal how in musical practices, "space is both produced and transformed" (p. 20). Furthermore, Born emphasizes the capacity of music and sound to produce or transform the distinction between public and private experience through social and technological mediation. Therefore, "music and sound produce their own irreducible socialities and spatialities, which, however, are traversed by wider social relations" (p. 29).

Theorizing sonic experience as a manifold structured event as outlined above means to think of it as an assemblage. The category of assemblage, which only deals with relations of elements, shows an ecological way of thinking, characterized by the interaction of a variety of discursive and non-discursive as well as human and non-human actors and forces. Such an ecological thinking establishes a "general ecology" that is no longer committed to biological discourses and the relationship between living beings and their environment. A general ecology is concerned "with a multiplicity of environments that are intertwined and complement each other" (Esposito, 2017, p. 285) no matter whether it is a natural, social environment or an environment of machines or media.

Hörl (2017) considers the denaturalization of the concept of ecology as the indication of a fundamental shift in the current discursive formation. The breakthrough of ecological semantics in recent decades manifests itself as a symptom of this transformation and testifies to a "general ecologization of thinking" (Hörl, 2017, p. 3). Therefore, the concept of ecology not only "represents the center of a great transformation of the politics of concepts and theories", but is part of a "technologi- 
cal displacement of sense (Sinnverschiebung), which refers to the destruction and displacement of the traditional significative and hermeneutic sense culture through technology" (Hörl, 2015, p. 3). This new "technological condition" in the history of sense was instigated by what Hörl calls the "cybernetic natural state", characterized by a dissemination of information and communication technologies and a general control paradigm (cf. Hörl 2015). Historically, the process of cybernetization was initiated around 1900 and expedited with the computerization starting in the 1950s, culminating in the "Environmentalization" (Hörl, 2018). His notion of "becomingenvironmental" does not just refer to today's distribution of (digital) media in all spatiotemporal surroundings, as widely discussed under the term of "ubiquitous computing". Rather, the environmentalitarian condition also affects forms of power, subjectivity, knowledge and capital (Hörl 2018, p. 154). In his conceptualization of Environmentality, Hörl refers to Michel Foucault's late lectures on The Birth of Biopolitics (2008). There, Foucault (2008) describes a new type of governmentality which is not working through techniques of disciplinary control, but through "an environmental type of intervention instead of the internal subjugation of individuals" (p. 260). This "environmental technology" (Foucault 2008, p. 261), which thus no longer addresses the individual, operates by modulating the environment. Against this backdrop, Hörl (2018) emphasizes that behavior and its control become central:

That is why Environmentality constitutes the high point so far of cyberneticization: it now refers us to the newly environmental modes of exploiting and valorizing relations and affects in which subjectivity takes shape today, modes around which-and this is central here-a new behavioral economy establishes itself (p. 161).

In this regard, Hörl's reflections echo the main ideas of Gilles Deleuze's popular, but at the same time very vague and suggestive essay on control societies. The central hypothesis is that there have been shifts in the fundamental modalities of power, described by Foucault as societies of sovereignty and as disciplinary societies. ${ }^{2}$ Deleuze correlates control as a new type of power to a more general transformation of society and its economy, education, technology, politics etc. The panoptic view of Foucault's disciplinary society with its spatial enclosures and central viewpoints gives way to "open" milieus and the continuous creation of space. The difference between disciplinary and control society is defined by the production of space: "Enclosures are molds, distinct castings, but controls are a modulation, like a self-deforming cast that will continuously change from one moment to the other, or like a sieve whose mesh will transmute from point to point" (Deleuze, 1992, p. 4). Conceptually, the function of modulation, which in general is an important category in Deleuze's work, opposes molding, even though historically, they can overlap.

Modulation as a "self-deforming" process of the social marks a new kind of social self-regulation. In understanding control as self-regulation, it is isomorph to the 
cybernetic principle of feedback loops. In this more restrictive reading, Deleuze's idea is being closely related to Nobert Wiener's first generation of cybernetics (Williams, 2015). From the standpoint of Wiener's early cybernetic vision, everything can be thought of as feedback machines and thus be described in terms of abstraction, idealizing formalization in notions of computer and control circuits (Wiener, 1948). The human, social worlds appear as structures for technical and planning control. Consequently, Deleuze parallelizes the different forms of society with different machines. While the disciplinary societies are equipped with "energetic machines", the control society is symptomatic of the "computer" (Deleuze, 1992, p. 6). The digital computer is the technological manifestation of cybernetic and information theory's feedback loop.

However, Yuk Hui (2015) has recently emphasized that the concept of modulation should not be restricted to the concrete form of control as a technical process or as monitoring. He argues that "control societies [should be understood] as specific modes of modulation, that produce a homogeneous individuation or even a disindividuation" (p. 77). Hui suggests that modulation as a "metaphysical principle" produces control as a political form and appears equivalently as feedback in technology. In addition, a close similarity to Hörl's idea of Cyberneticization and Environmentality can be discerned here:

The generalmovement of normalization-whose power technologies (enclosing, parceling out, hierarchizing) Foucault had studied so carefully in his previous work and which could be characterized as power technologies of molding-yielded to a general movement of Environmentalization characterized by an entirely different form of intervention, a kind of nonintervention in the form of modulation (Hörl, 2018, p. 159).

Both Deleuze and Hörl diagnose a transformation process through which the principle of modulation becomes central. Modulation is not only a crucial principle for technologies and media, but also manifests itself politically as a power regime of control. Control no longer acts in a disciplinary mode, but as an "environmental technology".

Against this backdrop, I propose the notion of environment as a central concept for the following analysis. However, while space is one category among many in a larger assemblage, the term environment refers to a more general idea. An environment is not simply given, but always an environment of something or someone. Therefore, an environment describes a relationship by drawing a distinction between a subject and its surrounding. In distinction to the subject, the environment then addresses an assemblage of many complex and intertwined levels and elements. Thus, I suggest observing the unity of difference between subject and environment. Applying this observation scheme, the subjectivations in their relationship to environmental conceptualizations can be examined, and advertising 
narratives, self-descriptions as well as the inherent logics of the examples can be analyzed. Central to the inquiry is how environments and listening spaces are structured and co-produce forms of subjectivations. These observations will be short-circuited with the power-theoretical reflections of Deleuze and Hörl.

\section{Environmental modulation: Cancelling out "noise"}

Passive reduction of "noise", achieved by isolation or muffling, is a well-known cultural technique used all the way from Odysseus in ancient times to today, now in the form of headphones. Unlike these passive forms, noise-cancelling headphones operate with active compensation of noise by means of so-called active noise reduction or ANC. The acoustic principle behind this technology is destructive interference. Destructive interference refers to the phenomenon that two waves cancel each other out at half the path difference. The crest of one wave meets the trough of the other, so that the sum of the two equals 0 .

From the point of view of history of knowledge, interference as a basal quality of waves has been known in acoustics since its paradigm shift around 1800, i.e. in connection with the introduction of wave theory, and can be mathematically described since Hermann von Helmholtz's transfer of the Fourier theorem (Fourier, 1822) to the field of acoustics (Helmholtz, 1875). At the end of the 19th century, the phenomenon of interference and the more general principle of superposition of waves are well known. In a major work on the current state of knowledge on sound, Baron Rayleigh (1878) described how he produced a "Point of Silence" by superimposing a maxima and minima of loudness, using two electromagnetically synchronized tuning forks (pp. 104-106). Thus, he showed that sound fields interfere in the same way as optical fields, which has been known since the days of Thomas Young at the beginning of the 19th century.

Based on this knowledge, Paul Lueg, a doctor of philosophy and medicine who worked as a physician, submitted the first patent for active noise control in Germany in 1933 and one year later in the USA (cf. Guicking, 1990; Elliott and Nelson, 1990). In his patent for the "Process of Silencing Sound Oscillations" (U.S. Patent No. 2,043,416, 1934), Lueg described the idea of detecting sound waves using a microphone. The electromagnetic signal is phase-shifted and played back via loudspeakers to cancel the initial sound wave. In this way, the "disturbing" sound source should be eliminated. In his German patent ("Deutsches Reich" Patent No. 655,508, 1937), different examples for its usage are mentioned. Lueg suggests using the method of ANC to muffle windows and doors or even to create entire acoustic "walls", although one of the main areas of application, according to Lueg (1937), is the office:

Furthermore, the installation of apparatus manufactured according to this invention in window and door openings, etc., makes it possible to prevent sound vibra- 
tions from reaching the interior of rooms when passing through these openings or to subject them to damping. [...] It is also desirable in offices to muffle the annoying typewriter noise. According to the method of the invention, this can be done in a very simple way by recording only very specific frequencies of the sound vibrations, shifting them in phase and reproducing them on them ${ }^{4}$ (para. 4-5).

The example shows that Lueg apparently had the principle of today's ANC in mind, but greatly underestimated the difficulties of the technical implementation. Especially in office situations with several people not remaining stationary, a very complex acoustic situation arises, in which it is not possible to emit a phase-inverted signal at the correct distance between the noise source to be eliminated and the moving eardrums. This is backed up by the fact that technical materialization did not take place. It took almost a hundred years before Lueg's idea to equip windows with ANC again led to scientific research that slowly made Lueg's imaginations appear to be technically feasible (Lam et al., 2020).

In the mid-1950s, however, the American military developed headphones with active noise reduction for jet fighter pilots and astronauts (cf. McKinley, 2010). The space which in the case of Lueg's patent is not controllable on the scale of an entire office, is reduced to a small space between the tympanum and the headphone's speaker membrane. Another technically induced and, most importantly, controllable space is placed between the noise of the "outside" world and the listener.

At the turn of the millennium, the listening technology of ANC-based headphones was introduced to the global market. Bose's "QuietComfort" was the first consumer product. ${ }^{5}$ In current models, a real-time digital signal processor algorithmically computes the information from the microphones on and in the headphones in order to calculate the destructive interference. In real time, the sonic-spatial surrounding is eavesdropped and compared with the interior of the headphones which passively attenuates the sound from "outside". In this way, a boundary is drawn, along which the distinction between a new outside and inside is established and regulated. The environment is created not by the hylomorphism of molds, but by modulation: The boundary is based on permanent, algorithmic processes that transform the surroundings into an environment by processing their "information" and self-regulate the destructive signal in relation to the "outside".

In this perspective, the listening technology of noise cancelling appears as an instantiation of environmental modulation and as a cybernetic approach to the environment. To understand the form of subjectivation that accompanies this technology, I will examine the subject-environment relationship represented in current advertisements. In recent advertisings for Sony's new generation of noise-cancelling headphones, various everyday situations are presented, in which the headphones unfold their specific environmental impact. The main narrative in all commercials for the WF-1000XM3 shows a white, upper middle-class man putting on headphones 
and then navigating self-determinedly through social situations in the public space. ${ }^{6}$ The headphones appear as technology that liberates subject. This liberation is achieved, as instructively presented in the advertisements, by formatting the social and physical space.

One advertising clip (Sony Xperia India, 2018) portrays a loud and "disturbing" soundscape of an inner-city crossing. The protagonist, who is waiting at this busy intersection, regains control over himself and his environment by putting on headphones. The soundscape of the intersection retreats and the subject can suddenly move freely, symbolized by him dancing to music. Other pedestrians evade or join his dancing and move to the music. The advertisement, which takes on the perspective of the protagonist through the auditory design, shows a gesture of appropriation and thereby an adaptation of the environment into the world of the white male subject. In terms of information theory, the "noise" endangers the "signal flow" of the subject. By means of listening technology, the subject creates a self-controlled and self-induced environment and thus gains control over himself.

Another advertising clip (Sony, 2019) uses Lueg's example of the office. The white, male subject gains control over himself by fading out the noise of the open plan office - underlined by the chorus of the song used: "I just wanna be free" (Sony 2019, 00:48). It is striking that the sources of the noise are a woman and a person of color. Leaving aside the gendered and racialized aspects of the advertisements, insofar as the "other" gender and skin color are seen as controllable causes of the white man's disorder, a change in the conceptualization of the environment and its control is revealed in comparison with the initial considerations of implementing ANC. In contrast to Lueg's imagination of acoustically optimizing entire rooms, the headphones create a closed and mobile listening space that can be used for destructive interference. Algorithmically, the headphone processes any spatial and temporal change for its own adaptation (modulation). Thus, instead of organizing entire rooms for disciplinary purposes (mold), the principle becomes individualized and mobile.

\section{Subconsciously feeding the brain: Spotify's concentration playlist}

In the sphere of work, music always played an important role. Thus, the increasing number of users listening to work-from-home playlists during the COVID-19 pandemic does not indicate a new cultural practice. Historically, for example in times of pre-industrial work, a work song functioned "as a tool" (Korczynski, 2003, p. 318) and helped to organize work processes. Also, in Fordism/Taylorism the industrial production work in factories was often accompanied by music in order to combat boredom and improve work ethics, as studies of BBC's program Music While You Work has shown (Jones, 2005). As the recent decades have fundamentally changed mobile technologies and individualized the way people listen to music, music consump- 
tion in post-industrial workspaces has also been "privatized". As qualitative studies show, music becomes a means of creating a private sphere and space, especially in open plan offices (Dibben \& Haake, 2013). At the same time, this construction of the private in the public blurs the boundaries between them and transforms "private activity of music-listening into a public (but often individualized) behavior" (Dibben \& Haake, 2013, p. 168), used to optimize one's own work performance. Today, the streaming service Spotify (n.d.) is not only offering specific playlists for working, but also very popular playlists for "focus and concentration". The more than 50 official playlists curated by Spotify all promise to improve the concentration and thus increase the productivity of the accompanying activity such as working or learning, each with very different music.

According to their functional logics that are promising enhancements of the ability to concentrate, the aim of these playlists is to superimpose the irregular events of the environment with music. The emergence of such conceptualization of music, operating in the background, presupposes the notion of the relationship between consciousness and its environment which physiology and experimental psychology established in the second half of the 19th century. In fact, these empirical investigations have fundamentally modified the picture of how consciousness works (Crary, 1990; 1999). The main idea is to distinguish between greater and lesser degrees of presence, conscious and unconscious states, foreground and background structures. Wilhelm Wundt, for example, describes differentiations between ground zero as a total lack of consciousness via the subconscious to the steady flow of psychologically conscious thoughts, composed of individual elements that form complex ideas. Following this idea, Wundt characterizes a mood as a "rising" of subconscious states of mind:

When any psychical process rises above the threshold of consciousness, it is the affective elements which, as soon as they are strong enough, are what first become noticeable. They begin to force themselves energetically into the fixation-point of consciousness before anything is perceived of the ideational elements. This is the case whether the impressions are new or revivals of earlier processes. This is what causes the peculiar states of mind [eigenthümliche Stimmung] the reason for which we are usually unable to discover ${ }^{7}$ (Wundt, 1902, p. 237).

Wundt's explanation of moods exactly explicates the mentioned logic of concentration playlists: Perceptions, which are not actively perceived as such, but latently carried along in the subconscious, are at one and the same time able to influence the consciousness and increase the mood or concentration.

Today, as the names of popular focus and concentration playlists imply, music is used as "Brain Food" for self-optimization, to produce "Deep Focus" or to turn subjects into "All-Nighters". On the one hand, such notions follow Wundt's conception of consciousness, while, on the other hand, they draw on the listening practices of 
the 20th century. A prominent example of the historical precursors of this logic is the "Muzak Company", founded in the mid-1930s. Muzak sold music subscriptions to shops and hotels, but above all to companies, to fill their factories and offices with sound (cf. Jones \& Schumacher, 1992). In the mid-1940s, Muzak supplied many of the largest American companies with its music and became part of the sonic everyday life experience of many workers. Applied to the office, such background music was meant to establish a constructive relationship between the listening subjects, their bodies and the acoustic and spatial structure. According to the proclaimed idea, the music should synchronize the different bodies as well as the individual consciousness in terms of temporal organization, so that the performance of workers could be optimized and exploited. At the same time, the music should superimpose and mask the "noise" of the room, for example typewriters, telephones or conversations. The created environment eliminates disturbances and has a structuring effect on the working subjects in the temporal and spatial coordination.

In the mid-20th century and today, music and sound are used instrumentally for the purpose of increasing productivity. However, the transformation lies in the process of constructing an environment as individualized listening space and its implied form of subjectivation. Under the working and production conditions of Fordism/Taylorism, the music used in offices and factories was part of the idea of "social engineering" and was intended to improve as well as regulate the moods or the motivation of the workers (Jones \& Schumacher, 1992). The environment and its spatial formation as molds are centrally structured through music, as also selected and centrally organized by Muzak, for disciplining and regulating purposes.

Instead of such sonic top-down management, music is now used on an individual basis to regulate the auditory environment and "to serve for the internal needs of the individual" (Dibben \& Haake, 2013, p. 153). On the one hand, instead of formatting the space, they draw a boundary by erasing the external surroundings with a new sonic listening space. On the other hand, the attempt to influence subjects is no longer imposed on them from the outside as a disciplinary act. The control now functions more subliminally and is carried out by the subjects themselves, ostensibly under freedom, to increase the productivity of their work for the company. The same applies to music. The music is no longer centrally produced by a company like Muzak, curated and then reproduced in a space. The pre-curated playlists of Spotify are adapted to the specific listener by a modulating algorithm feedbacking data of previous listening behavior into the new selection.

Since subjects are no longer passively exposed to instrumental logics, this corresponds precisely to what is called a neoliberal form of subjectivation. Such neoliberal subjectivity can be characterized as "a reflexive relationship in which every Self is meant to contain a distance that enables a person to be literally their own business" (Gershon, 2011, p. 539). In neoliberal subjectivation, the Self distances itself 
from itself by understanding itself as the object of control. The cybernetic figure of an environment to be controlled and marginalized is repeated in the subject itself. The subject must treat itself as an environmental factor to be controlled. The power structure that was formerly manifested in the "external" environment of an office or factory is found in the subject itself. The listening space created by a concentration playlist which superposes all disturbing "noise", thus establishes an environment in opposition to the consciousness. This environment, in turn, is intended to positively affect consciousness.

\section{Conclusion}

The various examples show how, historically, different subject-environment relationships have been produced by technologies as well as by cultural practices. In turn, such relationships reveal specific forms of subjectivation that are established and actualized through the respective relationships to the environment. Listening techniques and technologies create a space and an environment through music and sound. Space and environment are not "neutral" categories, but elements of a material-discursive formation. In addition, they are part of the process that Hörl describes as "Environmentalization". However, the process of "Environmentalization" does not only take place at the level of practices linked to the technologies, but also at the level of the distribution and the technical functioning of the listening technologies. The embedding of sound technologies in the most diverse everyday environments has also led to a decisive step in the Environmentalization of music and listening practices. This new form of music and reception has been prominently conceptualized with the notion of "ubiquitous music" and "ubiquitous listening" (cf. Kassabian, 2013). From the perspective of general ecology, the interplay of these different levels and elements as well as the historical dimension of music becoming environmental can be examined and intertwined with a critical thinking of power.

In the Fordist era, listening technologies and techniques turned large spaces into controllable environments. Just as Lueg in the 1930s wanted to create a large area reduction system covering the entire room by reversing sound waves to minimize noise in the office, in the same era Muzak provided background music for shops, hotels, offices and factories. These two concepts of listening spaces, which aim to have productive effects on the body by transforming the environment through technical regulation, follow the idea of spatial enclosures, centrally organized and structured through music and sound. The auditory space created operates under the evolving regime of cybernetization, turning space into controllable environments, but still formats environments as enclosures or molds.

Today, the listening technologies and techniques have become more individualized: Noise-cancelling headphones realize Lueg's idea, reduced to the small space 
between the eardrum and the speaker membrane of the headphones, and Muzak fragments into a personalized "neo-Muzak", arranged into playlists (Anderson, 2015). The molding of the environment for "disciplining" purposes is delimited, liquefied and at the same time transferred to the subject in individualized form. By means of current listening techniques, the subjects create an environment for themselves, which is maintained in constant adaptation to external events-i.e., the listening behavior of the subjects or the acoustic-spatial events-through modulation. Such self-regulation for the optimization of the Self is based on external circumstances, such as the spatial-acoustic situation at the workplace. The external disciplining of subjects coexists and is intertwined with a new and more subliminal form of power. "Environmentalization", defined by the principle of modulation, goes hand in hand with a mode of power understood as "environmental technology", "reified" as control. Thus, you can observe not only a cybernitization of music and its listening technologies/practices, but also an "Environmentalization" of (sonic) power.

\section{References}

Anderson, P.A. (2015). Neo-Muzak and the Business of Mood. Critical Inquiry, 41(4), 811-840. https:// doi.org/10.1086/681787

Born, G. (2013). Introduction - music, sound and space: transformations of public and private experience. In: Ibid. (ed.), Music, Sound and Space. Transformations of Public and Private Experience (pp. 1-70). Cambridge: Cambridge University Press. https://doi.org/10.1017/CBO9780511675850.001

Bull, M. (2000). Sounding out the City. Personal Stereos and the Management of Everyday Life. Oxford \& New York: Berg.

Bull, M. (2007). Sound Moves. iPod Culture and Urban Experience. London \& New York: Routledge.

Crary, J. (1990). Techniques of the Observer. On Vision and Modernity in the Nineteenth Century. Cambridge, MA \& London: MIT Press.

Crary, J. (1999). Suspensions of Perception. Attention, Spectacle, and Modern Culture. Cambridge, MA \& London: MIT Press.

Deleuze, G. (1992). Postscript on the Societies of Control. October, 59, 3-7.

DeNora, T. (2000). Music in Everyday Life. Cambridge: Cambridge University Press.

Dibben, N., \& Haake, A.B. Music and the construction of space in office-based work settings. In: Born, G. (ed.), Music, Sound and Space. Transformations of Public and Private Experience (pp. 151-168). Cambridge: Cambridge University Press. https://doi.org/10.1017/CBO9780511675850.008

Drott, E. (2018). Why the Next Song Matters: Streaming, Recommendation, Scarcity. Twentieth-Century Music, 15(3), 325-35. https://doi.org/10.1017/S1478572218000245

Elliot, S.J., \& Nelson, P.A. (1990). The active control of sound. Electronics \& Communication Engineering Journal, 2(4), 127-136. https://doi.org/10.1049/ecej:19900032

Eriksson, M., \& Johansson, A. (2017). “Keep Smiling!”: Time, Functionality and Intimacy in Spotify's Featured Playlists. Cultural Analysis, 16(1), 67-82.

Eriksson, M., Fleischer, R., Johansson, A., Snickars, P., \& Vonderau, P. (2019). Spotify Teardown. Inside the Black Box of Streaming Music. Cambridge, MA \& London: The MIT Press.

Esposito, E. (2017). An ecology of differences: Communication, the Web, and the question of borders. In: E. Hörl (ed.), General Ecology. The New Ecological Paradigm (pp. 285-302).. London: Bloomsbury Academic. 
Foucault, M. (2008). The Birth of Biopolitics. Lectures at The Collège De France, 1978-79. New York: Palgrave Macmillan.

Fourier, J.-B.J. (1822). Théorie analytique de la chaleur. Paris: Chez Firmin Didot, Père et Fils.

Gershon, I. (2011). "Neoliberal Agency". Current Anthropology, (52)4, 537-555. https://doi.org/10.1086/ 660866

Gilbert, J., \& Goffey, A. (2015). Control Societies: Notes for an Introduction. New Formation: A Journal of Culture/Theory/Politics, 84-85, 5-19. https://muse.jhu.edu/article/597730

Guicking, D. (1990). On the invention of active noise control by Paul Lueg. The Journal of the Acoustical Society of America, 87(5), 2251-2254. https://doi.org/10.1121/1.399195

Haberer, M. (2020). Versuch über Spotify, oder: Musikstreaming als Arbeit am Subjekt. In: Gálvez, J., Reichert, J., \& Willert, E. (eds.), Wissen im Klang. Neue Wege der Musikästhetik (pp. 145-161). Bielefeld: Transcript Verlag.

Hagood, M. (2019). HUSH. Media and Sonic Self-Control. Durham and London: Duke University Press.

Helmholtz, H.v. (1875). On the Sensations of Tone as a Physiological Basis for the Theory of Music [1863]. London: Longmans, Green \& Co.

Hörl, E. (2015). The Technological Condition. Parrhesia, 22, 1-15.

Hörl, E. (2017). Introduction to general ecology. The ecologization of thinking. In: Ibid. (ed.), General Ecology. The New Ecological Paradigm (pp. 1-73). London: Bloomsbury Academic.

Hörl, E. (2018). The Environmentalitarian Situation: Reflections on the Becoming-Environmental of Thinking, Power, and Capital, Cultural Politics, 14(2), 153-173. https://doi.org/10.1215/174321976609046

Hui, Y. (2015). Modulation after Control. New Formation: A Journal of Culture/Theory/Politics, 84-85, 74-91. https://muse.jhu.edu/article/597734

Jones, K. (2005). Music in factories: a twentieth-century technique for control of the productive self. Social \& Cultural Geography, 6(5), 723-744. https://doi.org/10.1080/14649360500258229

Jones, S.C., \& Schumacher, T.G. (1992). Muzak: On Functional Music and Power. Critical Studies in Mass Communication, 9(2), 156-169.

Kassabian, A. (2013). Ubiquitous Listening. Affect, Attention, and Distributed Subjectivity. Berkley, Los Angeles and London: University of California Press.

Korczynski, M. (2003). Music at Work: Towards a Historical Overview. Folk Music Journal, 8(3), 314-334.

Lam, B., Shi, D., Gan, W.-S., Elliott, S.J., \& Nishimura, M. (2020). Active control of broadband sound through the open aperture of a full-sized domestic window. Scientific Reports 10 (10021). https://doi.org/10.1038/s41598-020-66563-z

Lueg, P. (1934). U.S. Patent No. 2,043,416, n.p.: United States Patent Office.

Lueg, P. (1937 [1933]). "Deutsches Reich" Patent No. 655,508, n.p.: Reichspatentamt.

McKinley, R.L. (2010). Auditory and Acoustic Research \& Development at Air Force Research Laboratory (AFRL) (U.S. Air Force Report No. ADA539451). Retrieved July 20, 2020 from https://apps.dtic. $\mathrm{mil} / \mathrm{sti} / \mathrm{pdfs} / \mathrm{ADA} 539451 . \mathrm{pdf}$.

Prey, R. (2018). Nothing personal: algorithmic individuation on music streaming platforms. Media, Culture \& Society, 40(7), 1086-1100. https://doi.org/10.1177/0163443717745147

Rayleigh, J.W. Strutt. (1878). The Theory of Sound. Volume 2. London: Macmillan and Co.

Sony (05.07.2019). Sony Headphones WF-1000XM3 Official Advertisement Video. https://www.youtube.com/watch?v=lZ5FUkKBDqs

Sony Xperia India (11.10.2018). New Sony WH-1000XM3 Industry Leading Noise Cancelling Headphones. https://www.youtube.com/watch?v=1T1UeVZJT7s

Siegert, B. (2013). Cultural Techniques: Or the End of the Intellectual Postwar Era in German Media Theory. Theory, Culture \& Society, 30(6), 48-65. https://doi.org/10.1177/0263276413488963

Spotify (27.5.2020). Who I Am This Week. How At-Home Activities Are Inspiring New Playlists. Retrieved July 20, 2020 from https://newsroom.spotify.com/2020-05-27/how-at-home-activities-are-inspiring-new-playlists/. 
Spotify (n.d.a). Focus Playlists. Retrieved July 20, 2020 from https://open.spotify.com/genre/ focus-playlists.

Sterne, J. (2003). The Audible Past. Cultural Origins of Sound Reproduction. Durham \& London: Duke University Press.

Thrift, N. (2009). Space: The Fundamental Stuff of Geography. In: Clifford, N.J. et al. (eds.), Key Concepts in Geography (pp. 85-96) (2nd. ed.). London: Sage.

Wiener, N. (1948). Cybernetics: Or Control and Communication in the Animal and the Machine. Cambridge, MA: MIT Press.

Williams, A. (2015). Control Societies and Platform Logic. New Formation: A Journal of Culture/Theory/ Politics, 84-85, 209-227. https://muse.jhu.edu/article/597740

Wundt, W. (1902). Outlines of Psychology [1896]. Leipzig: Wilhelm Engelmann.

Zuboff, S. (2019). The Age of Surveillance Capitalism. The Fight for a Human Future at the New Frontier of Power. New York: PublicAffairs.

\section{Notes}

1 In the following, listening is understood as a learned, culturally formed practice intertwined with the development of media technologies. This follows Jonathan Sterne's notion of 'audile techniques' (Sterne, 2003, p. 96) and conceptualizes listening as a "cultural technique", "involved in operationalizing distinctions in the real" (Siegert, 2013, p. 61).

2 Other readings reject the understanding of control as new power mechanism and opt for a continuation of the disciplinary societies (cf. Gilbert \& Goffey, 2015).

3 Here and in the following, "noise" is not just referring to an entropic distribution of events in an audio spectrum, and neither is "noise" the opposite of music or part of other binary oppositions such as noise/signal or noise/silence. Instead, for this essay, "noise" is understood as the "unwanted" sound and thus subordinate to a perspective perceiving something (whatever it may be) as "noise".

4 The translation is my own.

5 Mack Hagood (2019) has examined Bose's advertising campaigns and exposed an explicitly racialized and gendered narrative (pp. 177-197), contrasting its conceptualization of "white noise" with the "black noise" in the advertisements of Beats by Dr. Dre, which address the everyday and structural racism (pp. 198-219).

6 Since the subjects depicted in Sony's advertisements are all white, upper middle-class men, these advertisements inscribe themselves into the racialized marketing narratives that Hagood (2019) emphasized.

7 The translation "peculiar states of mind" seems inappropriate in this context: The German Stimmung, as in the original text, is closer to the English "mood". Therefore, "peculiar mood" sounds more correct. 